\title{
BMJ Open Mental well-being and job satisfaction in general practitioners in Denmark and their patients' change of general practitioner: a cohort study combining survey data and register data
}

Karen Busk Nørøxe (D) ,1,2 Peter Vedsted, ${ }^{1}$ Flemming Bro, ${ }^{1,2}$ Anders Helles Carlsen, Anette Fischer Pedersen (D) 1,3

To cite: Nørøxe KB, Vedsted P, $\mathrm{Bro} \mathrm{F}$, et al. Mental well-being and job satisfaction in general practitioners in Denmark and their patients' change of general practitioner: a cohort study combining survey data and register data. BMJ Open 2019;9:e030142. doi:10.1136/ bmjopen-2019-030142

- Prepublication history for this paper is available online. To view these files, please visit the journal online (http://dx.doi. org/10.1136/bmjopen-2019030142).

Received 01 March 2019 Revised 01 October 2019 Accepted 04 October 2019

Check for updates

(c) Author(s) (or their employer(s)) 2019. Re-use permitted under CC BY-NC. No commercial re-use. See rights and permissions. Published by BMJ.

${ }^{1}$ Research Unit for General Practice, Aarhus, Denmark ${ }^{2}$ Department of Public Health, Aarhus University, Aarhus, Denmark

${ }^{3}$ Department of Clinical Medicine, Aarhus University, Aarhus, Denmark

Correspondence to Dr Karen Busk Nørøxe; karen_bn@live.dk

\section{ABSTRACT}

Objectives Low job satisfaction and poor well-being (eg, stress and burnout) among physicians may have negative consequences for patient experienced healthcare quality. In primary care, this could manifest in patients choosing another general practitioner (GP). The objective of this study was to examine change of GP (COGP) (unrelated to change of address) among patients in relation to their GPs' job satisfaction, well-being and self-assessed work-ability. Design and setting Data from a nationwide questionnaire survey among Danish GPs in May 2016 was combined with register data on their listed patients. Associations between patients' COGP in the 6-month study period (from May 2016) and the job satisfaction/well-being of their GP were estimated as risk ratios (RRs) at the individual patient level using binomial regression analysis. Potential confounders were included for adjustment.

Participants The study cohort included 569776 patients aged $\geq 18$ years listed with 409 GPs in single-handed practices.

Results COGP was significantly associated with occupational distress (burnout and low job satisfaction) in the GP. This association was seen in a dose-response like pattern. For burnout, associations were found for depersonalisation and reduced sense of personal accomplishment (but not for emotional exhaustion). The adjusted RR was $1.40(1.10-1.72)$ for patients listed with a GP with the lowest level of job satisfaction and 1.24 (1.011.52) and 1.40 (1.14-1.72) for patients listed with a GP in the most unfavourable categories of depersonalisation and sense of personal accomplishment (the most favourable categories used as reference). COGP was not associated with self-assessed work-ability or domains of well-being related to life in general.

Conclusions Patients' likelihood of changing GP increased with GP burnout and decreasing job satisfaction. These findings indicate that patients' evaluation of care as measured by COGP may be influenced by their GPs' work conditions and occupational well-being.

\section{BACKGROUND}

Among general practitioners (GPs) stress, burnout and job dissatisfaction is prevalent ${ }^{1}$
Strengths and limitations of this study

- Mental well-being and job satisfaction in general practitioners (GPs) were examined in relation to a register based (rather than a self-reported) indicator of suboptimal healthcare quality.

- Mental well-being and job satisfaction were assessed by validated rating scales.

- Precise linkage of each patient with a specific GP.

- Prospective study design.

- Adjustment for several potential confounders, but observed associations could still be mediated by unmeasured factors.

and may have important implications for quality in healthcare. ${ }^{2-7}$ Yet, existing research examining the possible consequences of physician mental well-being/satisfaction for healthcare quality predominantly rely on physician self-report.

Patient satisfaction is by itself an essential component of healthcare quality and may furthermore reflect underlying dimensions of healthcare quality important for health outcomes. Such dimension include access to care and effectiveness of clinical and interpersonal care. ${ }^{8}$ The possible negative implications of GP distress for patients' experience and satisfaction with primary healthcare is understudied.

A change of GP (COGP) that is unrelated to change of address (because of moving) may indicate dissatisfaction with the GP. ${ }^{9-11}$ The continuous relationship with a GP is highly valued by many patients, ${ }^{12}$ and a patient's COGP is often preceded by careful consideration. ${ }^{13}$ Satisfaction and decision-making regarding COGP is strongly influenced by the patient's perception of interpersonal aspects of care. ${ }^{9}$ 13-15 GPs who face stress, burnout 
and low job satisfaction may compromise with the quality of provided care and exhibit reduced empathic concern for the patients. ${ }^{71617}$ Moreover, GPs with high levels of occupational distress may have longer waiting times for consultations due to excessive workloads which could add to the listed patients' propensity to change GP. ${ }^{9}{ }^{10}$ Consequently, the patient-GP relationship and the patientassessed quality may suffer, and some patients may decide to change GP.

This study aimed to examine whether distress levels and self-assessed work-ability in GPs were associated with COGP among listed patients (voluntary disenrolment) as proxy for dissatisfaction with care.

\section{METHODS \\ Setting}

Almost all citizens in Denmark (98\%) are listed with a specific general practice which they must consult for medical advice. GPs in Denmark provide comprehensive family medicine to their listed patients and act as gatekeepers and coordinators to the rest of the tax-funded healthcare system. ${ }^{18}$ Patients are charged a fee (approximately €26) if they change general practice unrelated to change of address. Approximately, 27\% of Danish GPs are organised in single-handed practices.

\section{Study population}

In May 2016, we invited all GPs in Denmark to participate in a questionnaire survey on their working conditions and mental well-being (response rate: $50.2 \%$ ). The survey has been described in detail elsewhere. ${ }^{1}$ For the purpose of this study, only GPs in single-handed practices were included as this allowed for accurate linkage of each patient to a specific GP. Furthermore, we did not include GPs who had locum(s) employed for $>20$ hours per week, GPs with $<500$ listed patients and GPs who were newcomers in their current practice (ie, arrived in 2016).

GPs were excluded if more than $90 \%$ of the listed patients changed GP in the study period, or if more than $10 \%$ of the listed patients changed GP on the same date as this indicated restructuring of the practice $(n=7)$.

Study cases were patients aged $\geq 18$ years who were registered in the Danish Patient List Register (PLR) with an eligible general practice at the beginning of the study period. The PLR holds information on start and end dates of all registrations of patients with all general practices in Denmark. The 6-month study period started on 1 May 2016. A total of 569776 patients listed with 402 GPs in single-handed practices were included in the analyses.

\section{Change of GP}

A patient's COGP was defined as being listed in the PLR with a start date with a general practice in the study period and no new postal address or immigration within 2 months on both sides of the start date. Information on change of address and immigration among patients was collected from the Danish Civil Registration System.

\section{GP mental well-being and job satisfaction}

The indicators of mental well-being (general and occupational) and job satisfaction were selected a priori from the GP questionnaire. The indicators were measured by validated and reliable rating scales, which have previously shown adequate consistency among Danish GPs. ${ }^{1}$ Job satisfaction was assessed by the Warr-Cook-Wall Job Satisfaction Scale, perceived stress in general life by Cohen's 10-item Perceived Stress Scale, general well-being by the 5-item WHO Well-Being Index (WHO-5) and burnout by the Maslach Burnout Inventory Human-Services-Survey (MBI-HSS). The MBI-HSS consists of three subscales that measure three burnout dimensions: emotional exhaustion, depersonalisation and sense of personal accomplishment. Self-rated work-ability was measured by a single-item of the Work Ability Index; the respondents scored their current work-ability against their lifetime best on a Likert scale. This single item has shown high consistency with the full scale. $^{19}$

We categorised job satisfaction, perceived stress, self-rated work-ability and each burnout dimension according to quartiles of the scale scores. No well-established cut-off values exist that define significant positive or negative levels of these measures. Burnout is often categorised according to the cut-off value based on normative frequency distributions; this approach allows for comparison of burnout symptoms over time and across populations, but it does not signify clinical significance. ${ }^{20}$ As in previous research, we categorised scales according to quartiles of the sum-scores to allow for exploration of non-linear and dose-response like associations with COGP. ${ }^{21} 22$ To evaluate burnout as a multidimensional construct, ${ }^{20}$ we additionally categorised burnout based on a composite burnout score. ${ }^{22}$ This score was calculated by adding up points corresponding to the quartile of each subscale (reversed score for personal accomplishment); one point was assigned for subscale scores in the first quartile, and two, three and four points were assigned for scores in the second, third and fourth quartiles, respectively. The composite score was categorised into five groups: 3-4 points (corresponding to low burnout levels on all subscales), 5-6 points, 7-8 points, 9-10 points and 11-12 points (corresponding to high burnout levels on all subscales). Finally, general well-being was categorised as 'poor' for a scale score of $\leq 50$ (the recommended cut-off value when using the WHO-5 for screening for depression), 'good' for a score of $>70$ and 'moderate' for a score in between. ${ }^{1}$

\section{Covariates}

Potential confounders were selected a priori for adjustment. At GP level, information on gender and seniority (years since qualification as a GP: $\leq 5,6-15,16-25$ or $\geq 25$ ) was obtained from the questionnaire survey. At patient level, information on each patient's demographic and socioeconomic characteristics was obtained from Statistics Denmark. ${ }^{23}$ This information included gender, age group at the beginning of the study period (18-29, 
$30-39,40-49,50-59,60-69,70-79$ or $\geq 80$ years), marital status (married/cohabiting or living alone), ethnic origin (Dane or immigrant/descendent), degree of urbanisation (rural area: $<1000$ inhabitants, small city: 1000-19 999 inhabitants, medium city: 20000-99 999 inhabitants or large city: >1000000 inhabitants), OECD-modified household income (categorised in pentiles), highest attained educational level (low: $\leq 10$ years, medium: 11-15 years or high:>15 years), work affiliation (in the labour force: employed and students, outside the labour force. unemployed, early retirement pensioner, personal or sick leave, or retired).

Multimorbidity in patients was assessed by Charlson's Comorbidity Index score (0, 1, 2 or $\geq 3)$, which was calculated on the basis of the diagnoses registered in the Danish National Patient Register in 2006-2015. ${ }^{24}$ Finally, the percentage of general practices closed for intake of new patients in the patients' municipality in 2016 $(<60 \%, 60 \%-80 \%$ or $>80 \%)$ was included as a covariate obtained from the Organisation of General Practitioners in Denmark ${ }^{25}$ because the patient's option to change general practice depends on the availability of alternative practices. ${ }^{9}$ GPs are generally allowed to close for intake of new patients when their list size exceeds 1600 patients per GP.

Information on socioeconomic characteristics was obtained for 2015. Missing information on educational level $(5.9 \%)$ was categorised as unknown. Patients with missing information on any other covariates were excluded $(n=5.213(0.9 \%))$. Each patient was linked to the GP-related data through the GP's provider number. ${ }^{1}$ At patient level, the data were linked through the civil registration number $(\mathrm{CRN})$; a unique personal identification number assigned to all citizens in Denmark. ${ }^{26}$ All personal identifiers were encrypted prior to analysis. ${ }^{1}$

\section{Analyses}

We calculated the share of patients with COGP and the corresponding 95\% CI. Associations between each of the included GP well-being indicators and COGP among patients were calculated at the individual patient level by use of binomial regression analyses. The most favourable category of the indicator examined was used as reference. Unadjusted and adjusted analyses were carried out using robust variance estimation to account for clusters of patients at practice level. Adjusted models included share of practices closed for new patient uptake in the municipality, GP factors (gender and seniority) and patient factors (gender, age, marital status, ethnicity, city size, income, length of education, work affiliation, comorbidity) in the categories described above.

Prior to these analyses, we tested that the mean time at risk of COGP per listed patient did not vary across the GP well-being/satisfaction categories. Patients were considered to be at risk until death, immigration or change of general practice for any reason.

A $p$ value of $\leq 0.05$ was considered statistically significant. Analyses were performed using Stata V.15.

\section{Patient and public involvement}

This research was done without patient or public involvement.

\section{RESULTS}

During the 6-month study period, we identified 6648 $(1.17 \%)$ cases of COGP among the included patients (ie, COGP without change of address). The characteristics of the study cohort $(n=569776)$ and the share of patients with COGP are shown in table 1.

Table 2 displays GP characteristics and well-being.

Table 3 shows the results of the regression analyses.

The likelihood of COGP increased with depersonalisation, diminishing sense of personal accomplishment and decreasing job satisfaction in the GP with whom the patient was listed. The adjusted RR was 1.40 (1.10-1.72) for patients listed with a GP with the lowest level of job satisfaction and 1.24 (1.01-1.52) and 1.40 (1.14-1.72) for patients listed with a GP in the most unfavourable categories of the burnout dimensions depersonalisation and sense of low personal accomplishment.

Likewise, COGP tended to increase with a higher composite burnout score, although a small decline was seen at the highest level of burnout. Yet, the emotional exhaustion dimension of burnout was not associated with COGP. Likewise, no associations were found for perceived stress, general well-being or self-assessed work-ability.

\section{DISCUSSION \\ Main findings}

Patients' likelihood of changing GP increased with decreasing job satisfaction in the GP with whom they were listed. Likewise, patients listed with a GP with high levels of depersonalisation, feelings of low personal accomplishment or a high composite burnout score were more likely to change GP compared with patients listed with a GP with low burnout scores. Notably, these relationships had a dose-response pattern, although a small decrease was seen for the highest composite burnout level. In contrast, COGP was unrelated to emotional exhaustion, perceived stress, general well-being and self-assessed work-ability in the GP.

\section{Strengths and limitations}

Major strengths of this study include the large sample size and the precise linkage of each patient to an individual GP by the combining of register-based data and survey data. The Danish national registers provide highly valid data. ${ }^{26}$ The survey data covered multiple distinct and yet interrelated aspects of GP well-being, which was measured by validated and reliable assessment scales. The categorisation of all variables were performed according to predetermined procedures. The sample size allowed us to rank GP wellbeing indicators using multiple categories, which enabled exploration of non-linear and dose-response like associations. Still, the categorisation might not distinguish the level 
Table 1 Patient characteristics according to COGP in the 6-month study period

\begin{tabular}{|c|c|c|c|}
\hline & & All patients & Patients with COGP \\
\hline & & N (\%) & n per $1000(95 \% \mathrm{Cl})$ \\
\hline Total & & $569776(100)$ & $11.7(11.4$ to 11.9$)$ \\
\hline Gender & Female & $287097(50.4)$ & $13.1(12.7$ to 13.6$)$ \\
\hline & Male & 282679 (49.6) & $10.2(9.8$ to 10.5$)$ \\
\hline Age group, years & $18-29$ & $116342(20.4)$ & $15.5(14.8$ to 16.2$)$ \\
\hline & 30-39 & $85453(15.0)$ & $13.7(12.9$ to 14.4$)$ \\
\hline & $40-49$ & $96114(16.8)$ & $11.1(10.4$ to 11.7$)$ \\
\hline & $50-59$ & $94716(16.6)$ & 9.5 (8.9 to 10.1$)$ \\
\hline & $60-69$ & $83667(14.7)$ & 9.1 (8.5 to 9.8$)$ \\
\hline & $70-79$ & $61533(10.8)$ & $10.1(9.3$ to 10.9$)$ \\
\hline & $\geq 80$ & $31951(5.6)$ & $10.3(9.3$ to 10.9$)$ \\
\hline Marital status & Married/cohabiting & $343049(60.2)$ & $11.5(11.1$ to 11.9$)$ \\
\hline & Living alone & 226727 (39.8) & $11.9(11.5$ to 12.4$)$ \\
\hline Ethnicity & Danish & $491661(86.3)$ & $11.4(11.1$ to 11.8$)$ \\
\hline & Immigrant/descendant & $78115(13.7)$ & $13.1(12.3$ to 13.8$)$ \\
\hline Education, years & $\leq 10$ & $142070(24.9)$ & $12.5(11.9$ to 13.1$)$ \\
\hline & $11-15$ & $227689(40.0)$ & $10.8(10.4$ to 11.3$)$ \\
\hline & $>15$ & $166644(29.2)$ & $11.8(11.3$ to 12.4$)$ \\
\hline & Unknown & $33373(5.9)$ & $12.9(11.8$ to 14.2$)$ \\
\hline Work affiliation & In the labour force & $356016(62.5)$ & $11.4(11.0$ to 11.8$)$ \\
\hline & Outside the labour force & $85620(15.3)$ & $15.3(14.5$ to 16.2$)$ \\
\hline & Retired & $128140(22.5)$ & 9.9 (9.4 to 10.5$)$ \\
\hline OECD-modified household income, & 1st (low) & $113956(20.0)$ & $13.3(12.7$ to 14.0$)$ \\
\hline pentiles & 2nd & $113955(20.0)$ & $12.8(12.2$ to 13.5$)$ \\
\hline & $3 r d$ & $113957(20.0)$ & $11.5(10.9$ to 12.1$)$ \\
\hline & 4th & $113953(20.0)$ & $10.5(9.9$ to 11.0$)$ \\
\hline & 5th (high) & $113955(20.0)$ & $10.2(9.7$ to 10.8$)$ \\
\hline Multimorbidity index score & 0 & $460769(80.9)$ & $11.7(11.4$ to 12.1$)$ \\
\hline & 1 & $52485(9.2)$ & $11.6(10.8$ to 12.6$)$ \\
\hline & 2 & $31.899(5.6)$ & $11.0(9.8$ to 12.1$)$ \\
\hline & $\geq 3$ & $24633(4.3)$ & $11.2(10.0$ to 12.6$)$ \\
\hline Practices closed for patient intake in the & $<60 \%$ & $264254(46.4)$ & $12.1(11.7$ to 12.6$)$ \\
\hline municipality & $60 \%-80 \%$ & $200187(35.1)$ & $12.1(11.6$ to 12.6$)$ \\
\hline & $>80 \%$ & $105335(18.5)$ & 9.7 (9.1 to 10.3$)$ \\
\hline City size & Rural area & $89014(15.6)$ & $10.8(10.1$ to 11.5$)$ \\
\hline & Small city & $137286(24.1)$ & $11.7(11.1$ to 12.3$)$ \\
\hline & Medium city & 88920 (15.6) & $11.4(10.7$ to 12.1$)$ \\
\hline & Large city & $254556(44.7)$ & $12.1(44.7$ to 12.5$)$ \\
\hline Duration of GP-patient relationship & $<2$ years & $139880(24.6)$ & $17.4(16.7$ to 18.1$)$ \\
\hline & $2-8$ years & $203640(35.7)$ & $12.1(11.7$ to 12.6$)$ \\
\hline & $>8$ years & $226256(39.7)$ & 7.7 (7.4 to 8.1$)$ \\
\hline
\end{tabular}

COGP, change of general practitioner without change of address;

of poor well-being that may affect the patient-experienced quality of care. The restriction of the study period to 6 months reduced the risk of fluctuations in the mental state of the GP during the study period.
We assessed GP well-being prior to COGP and the GPs were unaware of the collection of data on COGP. Still, we cannot rule out that caring for a patient population with a high propensity to change GP could affect GP well-being. 
Table 2 Description of the GPs included in the study $(\mathrm{n}=402)$

\section{GP and practice characteristics}

\begin{tabular}{ll}
\hline $\begin{array}{l}\text { Gender, } \mathrm{n}(\%) \\
\text { Female }\end{array}$ & $178(44.3)$ \\
\hline Male & $224(55.7)$ \\
Age, years; mean (SD) & $56.4(8.4)$ \\
$\begin{array}{l}\text { Years since qualification as a GP, mean } \\
\text { (SD) }\end{array}$ & $18.9(9.4)$ \\
List size, median (IQI) & $1693(1544-1935)$ \\
COGP per 1000 listed patients, median & $9.4(5.9-14.7)$ \\
(IQI); range &
\end{tabular}

\section{Well-being and satisfaction}

Job satisfaction score (WCW-JSS), $\quad 50$ (40-58) median (IQI)

Emotional exhaustion score (MBI-HSS), 20 (13-28) median (IQI)

Depersonalisation score (MBI-HSS), 5 (3-8)
median (IQI)

Personal accomplishment score (MBI- 35 (31-38) HSS), median (IQI)

\begin{tabular}{|c|c|}
\hline \multicolumn{2}{|l|}{ Composite burnout score, $\mathrm{n}(\%)$} \\
\hline 3-4 (low) & $75(18.7)$ \\
\hline $5-6$ & $80(19.9)$ \\
\hline $7-8$ & $93(23.1)$ \\
\hline $9-10$ & $93(23.1)$ \\
\hline 11-12 (high) & $61(15.2)$ \\
\hline $\begin{array}{l}\text { Perceived general stress score (PSS- } \\
\text { 10), median (IQI) }\end{array}$ & $12(8-17)$ \\
\hline \multicolumn{2}{|l|}{ General well-being (WHO-5) } \\
\hline Good (score >70) & $121(30.6)$ \\
\hline Moderate & $197(49.7)$ \\
\hline Poor (score $\leq 50$ ) & $78(19.7)$ \\
\hline \multicolumn{2}{|l|}{ Self-assessed work-ability, n (\%) } \\
\hline Score 10 (best) & $81(20.4)$ \\
\hline Score 9 & $122(30.8)$ \\
\hline Score 8 & $111(28.0)$ \\
\hline Score 7 & $82(20.7)$ \\
\hline
\end{tabular}

Number of GPs varies due to partial response to the questionnaire for six GPs.

COGP, change of general practitioner without change of address; IQI, interquartile interval; MBI-HSS, Maslach Burnout Inventory Human-Services-Survey; PPS-10, Cohens Perceived Stress Scale; WCW-JSS, Warr-Cook-Wall Job Satisfaction Scale; WHO-5, WHO Well-Being Index.

We used COGP as a proxy for dissatisfaction with the GP. The literature support COGP as a valid indicator of patient-assessed quality. ${ }^{9-11}$ Still, other explanation than dissatisfaction with GP care may account for some patients' COGP. Moreover, patients change GP after careful consideration; some may even stay with their GP
Table 3 Patients' COGP in relation to GP's job satisfaction, well-being and self-assessed work-ability

\begin{tabular}{|c|c|c|}
\hline & RR (95\% Cl) & adj. $\mathbf{R R}^{*}(95 \% \mathrm{Cl})$ \\
\hline \multicolumn{3}{|c|}{ Job satisfaction (quartiles) } \\
\hline 4th (high) & 1.00 & 1.00 \\
\hline $3 r d$ & $\begin{array}{l}1.08 \text { (0.87 to } \\
1.33)\end{array}$ & 1.08 (0.88 to 1.32$)$ \\
\hline 2nd & $\begin{array}{l}1.21 \text { ( } 0.98 \text { to } \\
1.49)\end{array}$ & 1.21 (1.01 to 1.48$)$ \\
\hline 1st (low) & $\begin{array}{l}1.36 \text { (1.08 to } \\
1.71)\end{array}$ & 1.40 (1.10 to 1.72$)$ \\
\hline
\end{tabular}

Emotional exhaustion

(quartiles)

\begin{tabular}{|c|c|c|}
\hline 1st (low) & 1.00 & 1.00 \\
\hline 2nd & $\begin{array}{l}1.00(0.80 \text { to } \\
1.25)\end{array}$ & $1.05(0.85$ to 1.31$)$ \\
\hline $3 r d$ & $\begin{array}{l}0.88 \text { (0.72 to } \\
1.09)\end{array}$ & $0.92(0.76$ to 1.13$)$ \\
\hline 4th (high) & $\begin{array}{l}1.03 \text { (0.31 to } \\
1.28)\end{array}$ & 1.04 (0.86 to 1.27$)$ \\
\hline \multicolumn{3}{|c|}{ Depersonalisation (quartiles) } \\
\hline 1st (low) & 1.00 & 1.00 \\
\hline 2nd & $\begin{array}{l}1.15 \text { (0.94 to } \\
1.42)\end{array}$ & $1.18(0.98$ to 1.44$)$ \\
\hline $3 r d$ & $\begin{array}{l}1.15 \text { (0.93 to } \\
1.43)\end{array}$ & 1.22 (0.99 to 1.50$)$ \\
\hline 4th (high) & $\begin{array}{l}1.21 \text { ( } 0.98 \text { to } \\
1.50)\end{array}$ & $1.24(1.01$ to 1.52$)$ \\
\hline
\end{tabular}

Personal accomplishment

(quartiles)

$\begin{array}{lll}\text { 1st (high) } & 1.00 & 1.00 \\ \text { 2nd } & 1.10(0.88 \text { to } & 1.13(0.91 \text { to } 1.39) \\ & 1.37) & \\ \text { 3rd } & \begin{array}{l}1.27(1.06 \text { to } \\ \text { 1.52) }\end{array} & \mathbf{1 . 3 4}(\mathbf{1 . 1 2} \text { to } \mathbf{1 . 5 9}) \\ \text { 4th (low) } & \begin{array}{l}1.36(1.09 \text { to } \\ \text { 1.69) }\end{array} & \mathbf{1 . 4 0}(\mathbf{1 . 1 4} \text { to } \mathbf{1 . 7 2}) \\ & \end{array}$

\section{Composite burnout score}

\begin{tabular}{|c|c|c|}
\hline 3-4 (low) & 1.00 & 1.00 \\
\hline $5-6$ & $\begin{array}{l}1.16(0.92 \text { to } \\
1.47)\end{array}$ & $1.15(0.92$ to 1.44$)$ \\
\hline $7-8$ & $\begin{array}{l}1.24 \text { (1.00 to } \\
1.53)\end{array}$ & 1.30 (1.06 to 1.58$)$ \\
\hline $9-10$ & $\begin{array}{l}1.30(1.05 \text { to } \\
1.61)\end{array}$ & $1.38(1.12$ to 1.71$)$ \\
\hline 11-12 (high) & $\begin{array}{l}1.22(0.96 \text { to } \\
1.56)\end{array}$ & 1.21 (0.96 to 1.52$)$ \\
\hline
\end{tabular}

$\begin{array}{lll}\text { Perceived stress (quartiles) } & & \\ \text { 1st (low) } & 1.00 & 1.00 \\ \text { 2nd } & 1.01(0.82 \text { to } & 1.04(0.86 \text { to } 1.25) \\ & 1.24) & \\ \text { 3rd } & \begin{array}{l}1.13(0.90 \text { to } \\ 1.42)\end{array} & 1.17(0.93 \text { to } 1.46) \\ & \begin{array}{l}0.99(0.82 \text { to } \\ \text { 4th (high) }\end{array} & 0.96(0.80 \text { to } 1.15)\end{array}$

General well-being 


\begin{tabular}{|c|c|c|}
\hline & RR $(95 \% \mathrm{Cl})$ & adj. $\mathrm{RR}^{\star}(95 \% \mathrm{Cl})$ \\
\hline Good & 1.00 & 1.00 \\
\hline Moderate & $\begin{array}{l}1.06(0.89 \text { to } \\
1.27)\end{array}$ & 1.07 (0.89 to 1.27$)$ \\
\hline Poor & $\begin{array}{l}1.02 \text { ( } 0.83 \text { to } \\
1.25)\end{array}$ & $1.01(0.82$ to 1.24$)$ \\
\hline \multicolumn{3}{|c|}{ Self-assessed work-ability } \\
\hline 4th (high) & 1.00 & 1.00 \\
\hline $3 r d$ & $\begin{array}{l}0.94 \text { ( } 0.75 \text { to } \\
1.17)\end{array}$ & 0.98 (0.79 to 1.22$)$ \\
\hline 2nd & $\begin{array}{l}1.09 \text { (0.86 to } \\
1.38)\end{array}$ & 1.13 (0.91 to 1.42$)$ \\
\hline 1st (low) & $\begin{array}{l}0.92(0.73 \text { to } \\
1.15)\end{array}$ & $0.92(0.74$ to 1.15$)$ \\
\hline
\end{tabular}

Bold indicates significant results $(p \leq 0.05)$.

${ }^{*}$ Adjusted for patient age, gender, socioeconomic factors, multimorbidity, city size, duration of GP-patient relationship and percentage of practices closed for patient intake in the municipality (categorised as presented in table 1) and for GP seniority and gender. COGP, change of general practitioner without change of address; RR, risk ratio.

even if they are dissatisfied and have a poor relationship with their GP. ${ }^{91314}$ COGP is a rare event $(1.17 \%$ of patients in the study) and may capture only major dissatisfaction while leaving minor dissatisfaction undetected. These matters impair the use of COGP as a proxy for patient satisfaction and could result in an underestimation of the influence of GP-related factors on patient satisfaction. In addition, not all patients consult their GP on a regular basis, which could leave some of the study cases 'unexposed' to their GP, which may also increase the risk of an underestimation.

Factors beyond the control of the GP may affect patients' COGP and could thus confound the results if inadequately controlled for. First, patient factors are important determinants of COGP, and bias related to patient characteristics may occur. For instance, complex healthcare needs in patients may relate to GP distress ${ }^{27}$ as well as to patients' propensity to change GP. As seen from table 1, patients inclined to COGP seem to include patients who were more likely to consult with complex healthcare needs (eg, patients outside the labour force) and patients who were less inclined to consult with complex needs (eg, younger people). Overall, the role of case-mix of patients is complex and may confound the results in both directions. Next, the likelihood of COGP in response to poor care may decrease with the availability of alternative practices locally. A high number of practices closed for patient intake may reflect workforce shortage, which may be associated with increased levels of GP workload and occupational distress. ${ }^{28}$ Therefore, we adjusted for a lack of alternative practices. If inadequately adjusted for, this would most likely result in an underestimation of the observed relationship between GP distress and COGP in patients. Additionally, unmeasured characteristics of the
GPs and their clinics (eg, personality, clinical skills and work conditions) could confound the results. Overall, we adjusted for several potential confounders and we believe that unmeasured confounding is unlikely to fully account for the observed associations.

The study population was restricted to patients listed with GPs in single-handed practices who responded to the survey which could impair generalisability of findings. Yet, we have no reason to assume that the associations examined depended on the GPs' approach to participation or on the type of practice. The prevalence of burnout and low job satisfaction was the same for GPs in single-handed practices and GPs in partnership practices. ${ }^{1}$

\section{Comparison with the literature}

To our knowledge, only one previous study has explored the possible impact of physician well-being/satisfaction on patients' evaluation of healthcare by using COGP among patients as an indicator of dissatisfaction with care. ${ }^{29}$ Lower levels of job satisfaction were associated with a higher propensity to change GP in patients with pain, whereas no such relationship was seen in patients with depression. For both patient groups, however, patients of physicians with greater job satisfaction reported greater levels of trust and confidence in their physician. ${ }^{29}$ In line with our findings, the existing body of research suggests that higher levels of job satisfaction in physicians induce higher levels of patient satisfaction ${ }^{30}$ and better patientphysician relationships. ${ }^{7}$

For burnout, the results of a recent review and metaanalysis examining the potential implications of physician burnout on patient-assessed quality were in accordance with our findings; depersonalisation and low sense of personal accomplishment were both significantly associated with reduced patient-reported satisfaction, whereas emotionally exhaustion was not. ${ }^{6}$ Several reviews support that physician burnout may reduce the patient-assessed quality of care, but they also point to the need for further research. $^{2-46}$

There is consistent evidence that the patient's perception of the GP-patient relationship is an important determinant of patient satisfaction ${ }^{31-33}$ and that interpersonal aspects of care strongly influence the decision-making regarding COGP. Not feeling recognised by the GP, poor communication and lack of confidence and trust in the GP have been identified as important drivers in patients' decision to change GP. ${ }^{913-15}$

Empirical research examining the potential impact of GP burnout and job satisfaction on interpersonal aspects of care is sparse, but theoretically, it is plausible that interpersonal aspects of care mediate the observed associations between occupational distress and COGP. Burnout has been described as an erosion of engagement initiated by loss of internal resources as a response to chronic job-related stress. ${ }^{20}$ A suggested consequence of burnout is a hesitation to invest resources in the job as an attempt to protect against further resource depletion. ${ }^{16}$ Hence, burned out GPs may be inclined to invest less in 
the relationship with their patients. Depersonalisation refers to the development of an emotional detachment to people related to work and involves lack of compassion and a cynical attitude towards patients.

Although reverse causality cannot be excluded, one study found that GPs with higher levels of job satisfaction asked more psychosocial questions and showed more affective communication. ${ }^{34}$ Other studies found that GPs with lower sense of personal accomplishment used less affective communication and were less patient-centred ${ }^{35}$ and that patients listed with more depersonalised and emotionally exhausted GPs were less satisfied with the consultations with their GP. ${ }^{36}$ However, other studies found no indications that burnout or job dissatisfaction impaired the quality of interpersonal care. ${ }^{37-39}$ Some of these differences may be attributable to different burnout definitions.

It may seem contradictory that emotional exhaustion was not associated with COGP, while clear associations were found for the remaining two burnout components and for job satisfaction. Different explanations may account for this. First, the influence of burnout on job performance may depend on the stage of burnout. ${ }^{340} \mathrm{In}$ the initial stage, emotional exhaustion may be the only symptom and by overstretching themselves GPs may compensate for the potential negative effects of adverse work conditions on patient care. ${ }^{41}{ }^{42}$ Moreover, high conscientiousness could be a risk factor for burnout. Thus, emotionally exhausted GPs may exhibit high levels of thoroughness and attentiveness to patients' needs in clinical encounters, and hence their patients may experience excellent care. ${ }^{3} 38$ In later stages of burnout, carelessness and disengagement may become more dominant. This possible mix of excellent care provision and compromised care provision in emotionally exhausted GPs may counterbalance each other in the analysis. The finding that the frequency of COGP tended to increase with the composite burnout score could supports this, as higher composite scores are likely to reflect later stages of burnout. Second, as for the traditional cut-off levels of burnout, our categorisation of emotional exhaustion might not be suitable for identifying the level of exhaustion that causes functional impairment. A too low cut-off value could attenuate measured relationships. ${ }^{3}$ Lastly, personal and professional values and attitudes that predispose to depersonalisation, low sense of personal accomplishment and dissatisfaction could influence clinical practice. ${ }^{43}$ Hence, the observed associations might reflect underlying attributes of the GP.

While COGP was associated with work-specific aspects of well-being, no associations were found for well-being measures related to life in general. This suggests that job-related factors are most essential in the relationship between provider well-being and patient-assessed quality of care. Yet, the actual work conditions (and not only the GPs' affective response to them) may play a causal role in this relationship. For instance, GPs with higher workloads may have longer waiting times and shorter consultations which could cause some patients to change GP. ${ }^{910}$

COGP among patients was not associated with the selfreported work-ability among GPs. Previously, we found lower self-reported work-ability as well as poor well-being in GPs to be associated with a higher rate of potentially preventable hospitalisations in listed patients which could indicate suboptimal primary healthcare provision. ${ }^{22}$ In the assessment of work-ability, GPs may attach much importance to more bio-medical aspects of care, such as the ability to diagnose and provide treatment according to the best medical standards. Most patients may not be qualified to judge such aspects and tend to focus more on the interpersonal aspects of care in their overall evaluation of quality. ${ }^{44}$

\section{Implications}

The study findings imply that GPs' occupational wellbeing and job satisfaction influence patient satisfaction measured as COGP. Hence, improving job satisfaction and engagement and combating burnout may improve patient-assessed quality of care.

The possible implications are highly important: GP distress is prevalent, and COGP among patients may reflect serious aspects of care quality. This lend support for the conception that attention should be paid to the work conditions and the well-being of healthcare providers in the pursuit of optimal healthcare. However, more research is needed to establish the connection between GP well-being and healthcare provision.

\section{Conclusion}

We found that patients' likelihood of changing GP increased with decreasing GP job satisfaction and increasing GP burnout. We found no association between COGP among patients and emotional exhaustion in the GP, whereas depersonalisation and reduced sense of personal accomplishment both increased the likelihood of COGP. Overall, the findings suggest that the degree to which the GP thrives in the job influences the patient assessed quality of care provided.

Contributors All authors contributed substantially to the design of the study. KBN performed the statistical analyses in consultation with AHC. KBN wrote the first draft of the article. AFP, FB, PV and AHC assisted in writing and revising the manuscript. All authors read and approved the final manuscript.

Funding This work was supported by the Danish National Research Foundation for Primary Care and by the Health Foundation. The funding bodies had no role in the conduction of the study or in the writing of the manuscript.

Competing interests None declared.

Patient consent for publication Not required.

Ethics approval The project was approved by the Danish Data Protection Agency (J.no. 2016-41-4648). According to Danish law, approval by the Danish National Committee on Health Research Ethics was not required as no biomedical intervention was performed. Respondents gave their content to participate by responding to the questionnaire. Personally identifiable information on GPs and patients were re-coded and anonymised at Statistics Denmark prior to data analysis.

Provenance and peer review Not commissioned; externally peer reviewed. 
Data availability statement Danish data protection regulations prohibit disclosure of data to any third party without prior permission from the Danish Data Protection Agency. Thus, the data from this study cannot be made publicly available.

Open access This is an open access article distributed in accordance with the Creative Commons Attribution Non Commercial (CC BY-NC 4.0) license, which permits others to distribute, remix, adapt, build upon this work non-commercially, and license their derivative works on different terms, provided the original work is properly cited, appropriate credit is given, any changes made indicated, and the use is non-commercial. See: http://creativecommons.org/licenses/by-nc/4.0/.

\section{ORCID iDs}

Karen Busk Nørøxe http://orcid.org/0000-0002-2520-104X

Anette Fischer Pedersen http://orcid.org/0000-0003-0253-3671

\section{REFERENCES}

1 Nørøxe KB, Pedersen AF, Bro F, et al. Mental well-being and job satisfaction among general practitioners: a nationwide crosssectional survey in Denmark. BMC Fam Pract 2018;19:1.

2 West CP, Dyrbye LN, Shanafelt TD. Physician burnout: contributors, consequences and solutions. J Intern Med 2018;283:516-29.

3 Rathert C, Williams ES, Linhart H. Evidence for the quadruple aim. Med Care 2018;56:976-84.

4 Dewa CS, Loong D, Bonato S, et al. The relationship between resident burnout and safety-related and acceptability-related quality of healthcare: a systematic literature review. BMC Med Educ 2017; $17: 195$.

5 Hall LH, Johnson J, Watt I, et al. Burnout, and patient safety: a systematic review. PLoS One 2016;11.

6 Panagioti M, Geraghty K, Johnson J, et al. Association between physician burnout and patient safety, professionalism, and patient satisfaction: a systematic review and meta-analysis. JAMA Intern Med 2018;178:1317-30.

7 Williams ES, Skinner AC. Outcomes of physician job satisfaction: a narrative review, implications, and directions for future research. Health Care Manage Rev 2003;28:119-39.

8 Campbell SM, Roland MO, Buetow SA. Defining quality of care. Soc Sci Med 2000;51:1611-25.

9 Nagraj S, Abel G, Paddison C, et al. Changing practice as a quality indicator for primary care: analysis of data on voluntary disenrollment from the English GP patient survey. BMC Fam Pract 2013;14:89.

10 Gandhi IG, Parle JV, Greenfield SM, et al. A qualitative investigation into why patients change their GPs. Fam Pract 1997;14:49-57.

11 Grooss K, Hjertholm P, Carlsen AH, et al. Patients with cancer and change of general practice: a Danish population-based cohort study. Br J Gen Pract 2016;66:e491-8.

12 Salisbury C, Sampson F, Ridd M, et al. How should continuity of care in primary health care be assessed? Br J Gen Pract 2009;59:e134-41.

13 Frederiksen HB, Kragstrup J, Dehlholm-Lambertsen B. Attachment in the doctor-patient relationship in general practice: a qualitative study. Scand J Prim Health Care 2010;28:185-90.

14 Frederiksen HB, Kragstrup J, Dehlholm-Lambertsen G. It's all about recognition! qualitative study of the value of interpersonal continuity in general practice. BMC Fam Pract 2009;10:1-8.

15 Federman AD, Cook EF, Phillips RS, et al. Intention to discontinue care among primary care patients: influence of physician behavior and process of care. J Gen Intern Med 2001;16:668-74.

16 Halbesleben JRB, Rathert C. Linking physician burnout and patient outcomes. Health Care Manage Rev 2008;33:29-39.

17 Maslach C, Schaufeli WB, Leiter MP. Job burnout. Annu Rev Psychol 2001;52:397-422.

18 Pedersen KM, Andersen JS, Sondergaard J. General practice and primary health care in Denmark. The Journal of the American Board of Family Medicine 2012;25:S34-8.

19 Ahlstrom L, Grimby-Ekman A, Hagberg M, et al. The work ability index and single-item question: associations with sick leave, symptoms, and health--a prospective study of women on long-term sick leave. Scand J Work Environ Health 2010;36:404-12.

20 Schaufeli WB, Leiter MP, Maslach C. Burnout: 35 years of research and practice. Career Dev Int 2009;14:204-20.
21 Pedersen AF, Sørensen JK, Bruun NH, et al. Risky alcohol use in Danish physicians: associated with alexithymia and burnout? drug alcohol depend. Elsevier Ireland Ltd 2016;160:119-26.

22 Nørøxe KB, Pedersen AF, Carlsen AH, et al. Mental well-being, job satisfaction and self-rated workability in general practitioners and hospitalisations for ambulatory care sensitive conditions among listed patients: a cohort study combining survey data on GPs and register data on patients. BMJ Qual Saf 2019.

23 Denmark S. Available: https://www.dst.dk/en/Statistik/dokumentation [Accessed 20 Aug 2018].

24 Thygesen SK, Christiansen CF, Christensen S, et al. The predictive value of ICD-10 diagnostic coding used to assess Charlson comorbidity index conditions in the population-based Danish national Registry of patients. BMC Med Res Methodol 2011;11:83.

25 PLO analyse. Praksis med lukket for tilgang [Practices closed for intake of patients], 2016. Available: https://www.laeger.dk/sites/ default/files/plo_analyse_praksis_lukket_med_tilgang.pdf [Accessed 20 Aug 2018].

26 Pedersen CB. The Danish civil registration system. Scand J Public Health 2011;39:22-5.

27 Pedersen AF, Vedsted P. Understanding the inverse care law: a register and survey-based study of patient deprivation and burnout in general practice. Int J Equity Health 2014;13:121.

28 Marchand C, Peckham S. Addressing the crisis of GP recruitment and retention: a systematic review. Br J Gen Pract 2017;67:e227-37.

29 Grembowski D, Paschane D, Diehr P, et al. Managed care, physician job satisfaction, and the quality of primary care. J Gen Intern Med 2005;20:271-7.

30 Scheepers RA, Boerebach BCM, Arah OA, et al. A systematic review of the impact of physicians' occupational well-Being on the quality of patient care. Int J Behav Med 2015;22:683-98.

31 Vedsted P, Heje HN. Association between patients' recommendation of their GP and their evaluation of the GP. Scand J Prim Health Care 2008;26:228-34.

32 Wensing M, Jung HP, Mainz J, et al. A systematic review of the literature on patient priorities for general practice care. Part 1: description of the research domain. Soc Sci Med 1998;47:1573-88.

33 Crow R, Gage H, Hampson S, et al. The measurement of satisfaction with healthcare: implications for practice from a systematic review of the literature. Health Technol Assess 2002;6.

34 Bensing JM, den B-MAvan, Boerma W, et al. The manifestation of job satisfaction in doctor-patient communication; a ten-country European study. Int J Pers Cent Med 2013;3:44-52.

35 Zantinge EM, Verhaak PFM, de Bakker DH, et al. Does burnout among doctors affect their involvement in patients' mental health problems? A study of videotaped consultations. BMC Fam Pract 2009;10:1-10.

36 Anagnostopoulos F, Liolios E, Persefonis G, et al. Physician burnout and patient satisfaction with consultation in primary health care settings: evidence of relationships from a one-with-many design. $J$ Clin Psychol Med Settings 2012;19:401-10.

37 Orton P, Orton C, Pereira Gray D. Depersonalised doctors: a crosssectional study of 564 doctors, 760 consultations and 1876 patient reports in UK general practice. BMJ Open 2012;2:e000274-8.

38 Ožvačić Adžić Z, Katić M, Kern J, et al. Is burnout in family physicians in Croatia related to interpersonal quality of care? Arch Ind Hyg Toxicol 2013;64:255-64.

39 Ratanawongsa N, Roter D, Beach MC, et al. Physician burnout and patient-physician communication during primary care encounters. $J$ Gen Intern Med 2008;23:1581-8.

40 Pedersen AF, Carlsen AH, Vedsted P. Association of GPs' risk attitudes, level of empathy, and burnout status with PSA testing in primary care. Br J Gen Pract 2015;65:e845-51.

41 Linzer M, Manwell LB, Williams ES, et al. Working conditions in primary care: physician reactions and care quality. Ann Intern Med 2009;151:28-36.

42 Maslach C, Leiter MP, Schaufeli W. Measuring burnout. Oxford Handb Organ Well Being 2009:86-108.

43 Bakker AB, Demerouti E, Sanz-Vergel Al. Burnout and work engagement: the JD-R approach. Annu. Rev. Organ. Psychol. Organ. Behav. 2014;1:389-411.

44 Rao M, Clarke A, Sanderson C, et al. Patients' own assessments of quality of primary care compared with objective records based measures of technical quality of care: cross sectional study. BMJ 2006;333:19-22. 